\title{
Study on the Key Factors for Enterprises Adopting XBRL Technology Based on TOE Framework
}

\author{
Wei Di \\ Department of Accounting \\ School of Economics and Management \\ Jiangsu University of Science and Technology \\ Zhenjiang, China 212003
}

\author{
Jing Xia \\ Department of Accounting \\ School of Economics and Management \\ Jiangsu University of Science and Technology \\ Zhenjiang, China 212003
}

\begin{abstract}
At present, the Extensible Business Reporting Language (XBRL) financial reporting has given rise to a study fever at home and abroad. And the development of application of XBRL has also been focused on by various industries and fields. This thesis presents the origin of XBRL and the latest domestic and foreign development studies and conducts investigations to the factors impacting on adopting and implementation of XBRL technology of enterprises by adopting study methods such as questionnaire method and mathematical statistics, etc. On the basis of factor analysis on the investigation results, by adopting TOE theory as the analytical framework, this thesis conducts analysis on the main factors separately on three perspectives of technology, organization and environment and conducts the check on structural equations. Also, this thesis puts forward the suggestions which are favorable to the further diffusion of XBRL on this basis.
\end{abstract}

Keywords-XBRL; TOE model; factor analysis; structural equation; factors

\section{INTRODUCTION}

XBRL was put forward by Charles Hoffman, a certified public accountant in Washington State, America in 1998. Its prototype is the "XFRML" (XML based Financial Reporting Markup Language) which is translated in to Chinese as “基于 XML 的财务报告标记语言”. It was a plan launched by the American Institute of Certified Public Accountants with the objective of providing a global enterprise information supply chain based on XML so that it will be convenient for information users to obtain, exchange and analysis. It was later renamed as XBRL. Through the years of studies and development, XBRL has been successfully applied in over 570 projects in 27 countries in the world and its potential advantages and effects have been proved in the practice.

Under the current situation of economic globalization, XBRL has been constantly accepted and promoted all over the world. In December, 2003, Shanghai Stock Exchange selected 50 listed companies as a pilot project on the application of XBRL financial information disclosure standardized system. In 2004, China firstly required all the public companies to carry out the financial reporting in XBRL model and issued the national standard of Information Technology-Data Interface of Accounting Software. In 2005, Shanghai and Shenzhen Stock
Exchange realized the submission of XBRL annual reporting of listed companies. In October, 2010, Ministry of Finance and the Standardization Administration of the People's Republic of China issued a series of standards including General Classification Standards for Accounting Standards for Business Enterprises and the XBRL Technical Specifications and launched the pilot projects nation-wide. These two sets of standards have laid the firm foundation for construction of scientific and perfect accounting informatization standard system which can be commonly used world-wide. This is the milestone of the national accounting informatization work and marks that our country has firmly entered in to the promotion and application phases of XBRL. However, currently, the special technical advantages of XBRL will not certainly be voluntarily applied and developed by the relevant ones on the interest chain. And the enterprises have always held the waitand-see attitude and lack the motivation to actively carry out the XBRL standard technology. So, what are exactly the reasons that impact the promotion and application of XBRL technology in enterprises? It is the thinking about this question that causes the study on the crucial factors on the adopting and diffusion of XBRL technical standards of domestic enterprises in this thesis.

On the basis of the literature study, this thesis understands the current basic opinions on the XBRL financial report measures of enterprises in Zhenjiang through the measure of questionnaire and discusses the various factors for adopting XBRL technology of enterprises from three perspectives including technological dimension, organizational dimension and environmental dimension of TOE model framework by referring to the TOE (Technology-OrganizationEnvironment) theory framework, combining with the investigation results in the questionnaire about adopting of XBRL innovation technology of enterprises. Also following specific studies are launched in this thesis:

(1) Under the TOE theory framework, try to put forward the factor model and study hypothesis on the adopting of XBRL technology of enterprises.

(2) Conduct the factor analysis according to the 21 original variables impacting the XBRL technical factor model.

(3) Summarize the technological factors, organizational factors and environmental factors impacting the adopting of 
XBRL technology of enterprises according to the common factors obtained from the factor analysis results.

(4) Conduct further check on the structural equations.

(5) Give solutions and suggestions according to the study conclusions.

\section{TOE FRAMEWORK AND RESEARCH HYPOTHESIS IN TECHNOLOGY ADOPTION RESEARCH}

The TOE framework (Technology-OrganizationEnvironment Framework) in this article was proposed by Tomatzky and Fleischer in The Processes of Technological Innovation [1] in 1990, which divides the factors of adoption and implementation of technological innovation by an enterprise and organization into three aspects: technical level, organizational level and environmental level. On the one hand, the systematic and operational characteristics of the TOE framework are widely supported by enterprises during the period of technology innovation research. Many studies have found that the decisive factors affecting the implementation of technology adoption can be divided into three aspects: technology, organization and environment and so on. Troshani and Rao find that the adoption of XBRL technology is significantly affected by the environment factors such as government authorization and policy support, and organization factors such as education, training and propaganda and so on. On the other hand, aiming at different innovative technology, there is otherness in specific contents of the three dimensions of technology, organization and environment in the TOE model, and the decisive factors are not the same finally. [2] The TOE model takes the internal and external factors of the organization and the natural advantages of XBRL into consideration. Because of its strong systematicness and clear structure, many scholars have applied it to the analysis of the influence factors of technology innovation. [3]

According to the theoretical framework of TOE, this paper regards the implementation and adoption of XBRL technology as a kind of enterprise innovation behavior, from the perspective of technology, organization and environment, explores all kinds of specific factors which affect the adoption of XBRL technology in enterprise, and tries to come up with the affecting factors model of the adoption of XBRL technology by enterprise in the TOE framework. "Fig. 1"

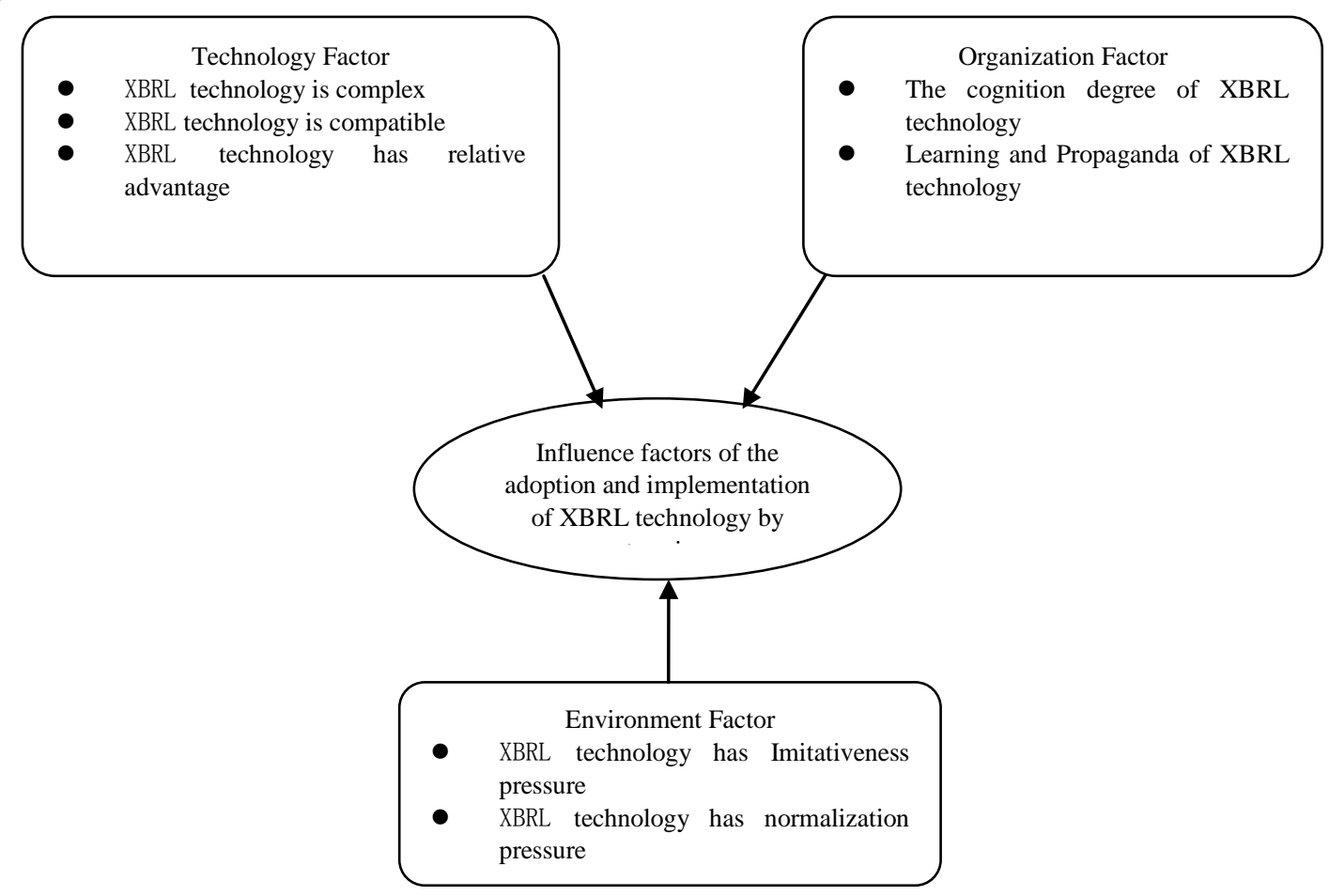

Fig. 1. The TOE model of influence factors of the adoption and implementation of XBRL technology by enterprises.

Technology factor as a primary factor in this model, can decide whether the enterprise can effectively adopt and popularize XBRL Technology, including technical complexity, technical compatibility, technical relative advantage, the disunity of cost and standard and so on. [4]-[6] Organization factor includes the enterprise scale, organizational structure, cognitive level, executive support and learning and propaganda and so on. Environment includes the industry rules and government policy of an organization, which can be summarized as imitativeness pressure and normalization pressure. The three factors are interrelated and restrict each other and the resultant force influences the behavior and speed of adopting and propagating XBRL technology by enterprise. We put forward the following hypothesis:

H1a: Technical complexity is a negative factor in adoption and implementation of XBRL technology by enterprises.

H1b: Technical compatibility is a positive factor in adoption and implementation of XBRL technology by enterprises. 
H1c: Technical relative advantage is a positive factor in adoption and implementation of XBRL technology by enterprises.

H2a: Cognitive degree is a positive factor in adoption and implementation of XBRL technology by enterprises.

$\mathrm{H} 2 \mathrm{~b}$ : Learning and Propaganda is a positive factor in adoption and implementation of XBRL technology by enterprises.

H3a: Imitativeness pressure is a positive factor in adoption and implementation of XBRL technology by enterprises.

H3b: Normalization Pressure is a positive factor in adoption and implementation of XBRL technology by enterprises.

\section{RESEARCH DESIGN}

\section{A. Data Collection and Sample Features}

This study applies a way of questionnaire and survey to test the model in different industries in Zhenjiang. The measurement items of the design and utilization of survey refer to the relevant research results at home and abroad, mostly from the classical literature in the field of organizational researches and management information systems. After designing a preliminary questionnaire, the author consults the relevant experts and makes a pre-survey, and corrects some existing problems in the questionnaire according to the results of pre-survey. In the model, the 23 primary variables of the first level index are established, and the formal questionnaire is formed. In the questionnaire, it applies the Likert Scale according to the survey of influence factor degree $(1=$ "very important", 5= "not important"), and the specific index variables and sources of literature in the model are shown in "Table III". After carefully revising, the final questionnaire applies the way of combining using network to fill with releasing on the spot to collect data, mainly by the following three ways: the questionnaire websites, university economic forums and releasing on the spot of enterprise. The recovery condition of questionnaire is as follows: 236 questionnaires are actually collected from the network websites; 78 questionnaires are actually collected from the University Economic Forum; 56 questionnaires were actually collected by the company on the spot. We screen out and eliminate some questionnaires which obviously have some problems in the 370 questionnaires. There are significant missing items, perfunctory questionnaires and similar questionnaires, and finally we get 300 valid questionnaires.

\section{B. Validity and Reliability Analysis}

1)Questionnaire Reliability Analysis: Reliability Analysis refers to an index which reflects the true degree of the measured feature according to the consistency or stability of the result by testing toll. The higher reliability of the scale is, and the smaller standard error of the measurement will make. The reliability of this scale is evaluated by Cronbach's Alpha coefficient, and the results are shown in Table 2. The Alpha coefficient of the overall questionnaire is 0.720 .
Although the reliability of overall questionnaire is reduced by the questionnaire sample, it is still greater than 0.7, which manifests that the reliability of overall questionnaire is acceptable. The alpha coefficient of technical complexity is 0.724; alpha coefficient of technical compatibility is 0.756 ; alpha coefficient of technical relative advantage is 0.774 ; alpha coefficient of technical cognitive degree is 0.792; alpha coefficient of learning and propaganda is 0.798 ; alpha coefficient of imitativeness pressure is 0.823 and alpha coefficient of normalization pressure is 0.779 . The results show that alpha coefficient of each dimensionality is above 0.7 and the reliability of each dimensionality is high which can be accepted by people.

Reliability Analysis refers to an index which reflects the true degree of the measured feature according to the consistency or stability of the result by testing toll. The higher reliability of the scale is, and the smaller standard error of the measurement will make. "Table I"

TABLE I. QUESTIONNAIRE RELIABILITY TESTING

\begin{tabular}{llll}
\hline Dimensionality & $\begin{array}{c}\text { Cronbach } \\
\text { Alpha }\end{array}$ & Dimensionality & $\begin{array}{c}\text { Cronbach } \\
\text { Alpha }\end{array}$ \\
\hline $\begin{array}{l}\text { Overall } \\
\text { Questionnaire }\end{array}$ & 0.720 & $\begin{array}{l}\text { Technical } \\
\text { Cognitive degree }\end{array}$ & 0.792 \\
$\begin{array}{l}\text { Technical } \\
\text { Complexity }\end{array}$ & 0.724 & $\begin{array}{l}\text { Learning and } \\
\text { Propaganda }\end{array}$ & 0.798 \\
$\begin{array}{l}\text { Technical } \\
\text { Compatibility }\end{array}$ & 0.756 & $\begin{array}{l}\text { Imitativeness } \\
\text { Pressure }\end{array}$ & 0.823 \\
$\begin{array}{l}\text { Technical } \\
\text { Relative } \\
\text { Advantage }\end{array}$ & 0.774 & Normalization & 0.779 \\
\hline
\end{tabular}

2)Validity Analysis of Questionnaires: Validity of questionnaires is to test the extent to which the questionnaire could measure the pre-test behavioral characteristics of the test. The validity of scale mainly is analyzed by factors analysis to examine the structure validity of the scale.

In the process of doing factor analysis, KMO and Bartlett tests are needed to test whether the questionnaire is suitable for factor analysis. Test results are showed in table 3 . The statistic of $\mathrm{KMO}$ is 0.729 , greater than 0.7 , which manifest that the factor analysis effects are good. The Bartlett test is now close to 0 , and there is a correlation between variables, which can be conducted for factor analysis. "Table II"

TABLE II. KMO AND BARTLETT TEST

\begin{tabular}{ccc}
\hline KMO & Kaiser-Meyer-Olkin & 0.729 \\
\hline & $\begin{array}{c}\text { Approximate Chi- } \\
\text { square }\end{array}$ & 2354.276 \\
Bartlett Sphericity Test & $\begin{array}{l}\text { Degree of } \\
\text { Freedom }\end{array}$ & 253 \\
& Significance & 0.000 \\
\hline
\end{tabular}


3)Extracting Common Factors and Named Explanation of Common Factors: In the process of doing factor analysis, in order to make the factor information more explicit and easier to explain, we apply the rotation method of maximum variance to rotate the factor. The factor results show that the cumulative contribution rate of 8 common factors to 23 variables is $70.861 \%$, greater than $70 \%$. The extraction results are in line with the theoretical construction, and the validity of the questionnaire is good and the typical variables of each factor are more prominent, which can be used to explain the main influence factors of the implementation of XBRL technology in enterprises. "Table III"

TABLE III. QUESTIONNAIRE FACTOR ANALYSIS RESULTS

\begin{tabular}{|c|c|c|c|c|c|c|c|c|}
\hline Item & Factor1 & Factor2 & Factor3 & Factor 4 & Factor 5 & Factor6 & Factor7 & Factor 8 \\
\hline Q1 & 0.772 & -0.096 & 0.046 & 0.033 & 0.113 & 0.179 & 0.186 & 0.071 \\
\hline Q2 & 0.821 & -0.041 & 0.088 & 0.052 & 0.070 & 0.046 & 0.105 & 0.192 \\
\hline Q3 & -0.078 & 0.780 & -0.096 & 0.100 & 0.100 & -0.019 & -0.017 & 0.067 \\
\hline Q4 & -0.079 & 0.752 & 0.100 & 0.199 & 0.064 & -0.005 & 0.025 & 0.040 \\
\hline Q5 & 0.025 & 0.822 & -0.081 & 0.015 & 0.058 & -0.036 & -0.077 & -0.013 \\
\hline Q6 & 0.044 & 0.008 & 0.841 & -0.010 & 0.006 & 0.140 & -0.016 & -0.040 \\
\hline Q7 & 0.099 & -0.111 & 0.769 & -0.037 & 0.050 & -0.041 & -0.035 & -0.001 \\
\hline Q8 & -0.017 & 0.023 & 0.844 & 0.019 & 0.032 & -0.001 & -0.010 & -0.071 \\
\hline Q9 & 0.041 & 0.054 & -0.104 & 0.788 & 0.135 & -0.029 & -0.063 & -0.068 \\
\hline Q10 & -0.044 & 0.066 & 0.047 & 0.818 & 0.107 & -0.006 & -0.036 & 0.021 \\
\hline Q11 & 0.094 & 0.196 & 0.025 & 0.843 & -0.040 & -0.007 & -0.003 & -0.014 \\
\hline Q12 & 0.065 & 0.123 & 0.004 & 0.089 & 0.828 & 0.063 & 0.014 & -0.011 \\
\hline Q13 & 0.133 & 0.079 & 0.055 & 0.088 & 0.825 & -0.025 & -0.045 & 0.010 \\
\hline Q14 & -0.016 & 0.023 & 0.033 & 0.029 & 0.837 & -0.014 & 0.030 & 0.085 \\
\hline Q15 & 0.026 & -0.122 & 0.076 & 0.041 & -0.028 & 0.681 & 0.256 & 0.178 \\
\hline Q16 & 0.050 & 0.016 & 0.000 & -0.057 & 0.038 & 0.863 & 0.166 & 0.130 \\
\hline Q17 & 0.170 & 0.025 & 0.035 & -0.027 & 0.011 & 0.845 & 0.187 & 0.097 \\
\hline Q18 & 0.079 & -0.076 & 0.011 & 0.007 & -0.030 & 0.216 & 0.848 & 0.074 \\
\hline Q19 & 0.097 & -0.076 & -0.041 & -0.029 & 0.021 & 0.197 & 0.882 & 0.048 \\
\hline Q20 & 0.130 & 0.071 & -0.045 & -0.091 & 0.010 & 0.158 & 0.753 & 0.118 \\
\hline Q21 & 0.175 & 0.055 & -0.045 & 0.005 & 0.019 & 0.206 & 0.085 & 0.787 \\
\hline Q22 & 0.007 & 0.070 & -0.026 & -0.061 & 0.027 & 0.198 & 0.060 & 0.823 \\
\hline Q23 & 0.096 & -0.019 & -0.050 & -0.006 & 0.043 & -0.006 & 0.088 & 0.821 \\
\hline Variance & & & & & & & & \\
\hline $\begin{array}{l}\text { Interpretation } \\
\text { Rate \% }\end{array}$ & 6.237 & 8.617 & 9.045 & 9.092 & 9.315 & 9.469 & 9.883 & 9.203 \\
\hline $\begin{array}{l}\text { Cumulative } \\
\text { Variance } \\
\text { Interpretation } \\
\text { Rate \% }\end{array}$ & 6.237 & 14.854 & 23.899 & 32.991 & 42.306 & 51.775 & 61.658 & 70.861 \\
\hline Factor Name & $\begin{array}{l}\text { XBRL } \\
\text { Technology } \\
\text { implementatio } \\
\mathrm{n} \text { and } \\
\text { diffusion }\end{array}$ & $\begin{array}{l}\text { Technical } \\
\text { Complexity }\end{array}$ & $\begin{array}{l}\text { Technical } \\
\text { Compatibility }\end{array}$ & $\begin{array}{l}\text { Technical } \\
\text { Relative } \\
\text { Advantage }\end{array}$ & $\begin{array}{l}\text { Technical } \\
\text { Cognitive } \\
\text { degree }\end{array}$ & $\begin{array}{l}\text { Learning and } \\
\text { Propaganda }\end{array}$ & $\begin{array}{l}\text { Imitativeness } \\
\text { Pressure }\end{array}$ & $\begin{array}{l}\text { Normalization } \\
\text { Pressure }\end{array}$ \\
\hline
\end{tabular}

IV. ANALYSIS OF INFLUENCE FACTORS BASED ON TOE MODEL

\section{A. Technology-----the Impact of Technical Factors on XBRL Implementation}

Technical factor as an important factor determines whether the enterprise is able to adopt and implement this innovative technology, from the perspective of technology level. The main influence factors of implementing XBRL technology by enterprise are in three aspects: technical complexity, technical compatibility and technical relative advantage, the three common factor and nine scale.

1)Technical complexity has certain impacts on the implementation of XBRL: When an innovative technology is relatively complex, the potential adopters may take longer time to comprehend and learn its function and effectiveness, in other words, the level of difficulty of use of technology can affect its adoption and diffusion degree. The complexity of XBRL technology comes from the integration of old and new systems and the process of information marking, and the difficulty of the marking process is the need to classify financial information according to the standards and give the corresponding marks. In principle of cost effectiveness, if the cost of using this technology is too large or the transition period is too long during system integration, it will cause the low efficiency, low benefit and negative impact to enterprise. Under this circumstance, most enterprises are inclined to decline the adoption of new technology. Therefore, complexity is a negative factor in adoption of XBRL technology.

2)The compatibility of technology has vital impacts on the implementation of XBRL: The compatibility of XBRL technology mainly includes organization compatibility and technology compatibility. Organization compatibility refers to the coordination degree of the existing value, cultural mentality, operation habit and demand structure of the potential adopters of enterprise organization and XBRL. If 
the adopters need to dramatically change the existing experience and value, coordination will loss and technology will not be adopted. However, technology compatibility refers to the compatibility and coordination degree of the existing systematic software and hardware facilities of the enterprise and XBRL. If IT technology and IT infrastructure still cannot meet the XBRL normal operation in the enterprise under the condition of increasing cost, enterprise will refuse to adopt the new technology. Therefore, technology compatibility is a positive factor in adoption of XBRL technology.

3)The relative advantage of technology is a crucial factor in the implementation of XBRL: The relative advantages of technological innovation are manifested in two aspects: economic benefits and non-economic benefits. When enterprise adopts a technological innovation, according to the cost effectiveness principle, the economic benefits are firstly taken into consideration, in other words, we need to do a financial budget, taking full account of the relationship between investment costs and expected benefits. If the new technology can bring more benefits to the enterprise on the basis of original production input, or reduce the cost, enterprises are inclined to adopt this dominant technology; otherwise, enterprise tend to refuse it. However, XBRL technology has natural advantages on financial information marking mode, the application of cross platform technology and the combination with IT technology, which can promote the enterprise to change the old business model and form a more efficient financial reporting process, and improve the reliability, comparability, transparency and accessibility of financial information, and thereupon the core competitiveness of enterprise will strengthen. Therefore, the relative advantage of technology plays a pivotal role in the enterprise acceptance and implementation of XBRL technology.

\section{B. Organization - the Influence of Organizational Factors on the Implementation of XBRL Technology.}

Organization factors mainly include organizational attributes which may affect enterprise to adopt new technology, such as perceptions and attitudes towards new technology, the degree of learning and propaganda and the availability of adequate financial resources. Therefore, from the perspective of organizational factors, the two main factors affecting the implementation of XBRL technology are cognitive degree, learning and propaganda, the two common factors and six scales.

1)The cognitive degree of XBRL is the decisive factor for enterprise to adopt XBRL technology: Because of the complexity of technology, enterprise will face some difficulties in applying to a new technology, and some enterprises will even generate barriers of organizational learning and then tend to refuse to adopt the new technology. In other words, if enterprises have a deep cognition and understanding on the usefulness and ease of use of XBRL technology, it can be more effective for enterprise to accept
XBRL technology. The specific aspects can be measured as follows: First, the attitudes of executives and decisionmaking supporter can promote enterprises to adopt XBRL. Executives are more simply to identify the potential development ability of new technology and can make a blueprint for future development, and their support can also attach the importance of XBRL technology to enterprise employees and benefit supply chain members. Second, the employee's cognition degree towards new technology. If the employees have full understanding and cognition on new technology, and can master the technical advantages skillfully and apply it to the actual financial work, and then the XBRL technology will develop and propagate smoothly in the company. Third, the enterprise's financial preparation for XBRL technology. Because the cost of adoption and application of XBRL is high, and the cost factor must be taken into consideration by the enterprise, meanwhile, the sufficient financial resources are also beneficial to attract innovative management and technical personnel. Therefore, the cognitive degree of XBRL is the important factor for enterprise to adopt XBRL technology.

2) Learning and propaganda degree are the important factors for enterprise to adopt XBRL technology: Compared with the traditional tools, the utilization of new technology has some knowledge obstacles and barriers. However, through external knowledge resource of XBRL technology, it can help enterprise organization accumulate more technical knowledge and help users study new technology to reduce the knowledge barriers. But the external resources of information channels need to correctly be guided and propagandized by the industry, and it will benefit the learning and propaganda of XBRL technology with the deeper degree and wider range. Therefore, learning and propaganda degree are the important factors for enterprise to adopt XBRL technology.

\section{Environment - the Influence of Environment Factors on the Adoption of XBRL Technology}

According to the TOE framework, environment factors are very crucial for enterprise to adopt XBRL technology innovation. The influence of environmental factors that come from the market, competitors, partners, government agencies, industry associations and XBRL suppliers outside the organization, which often bring the implementation pressure, policy support and industry improvement. From the perspective of environment, the two main factors affecting the implementation of XBRL technology are imitativeness pressure and normalization pressure, the two common factors and six scales.

1)Imitativeness pressure is an important factor for enterprise to adopt XBRL technology: Imitativeness pressure can lead enterprises to copy and imitate their competitors' actions to achieve success. There are two ways to present in detail: the first way derives from the attitude that other enterprises and organizations hold towards the implementation of new technology, that is, a kind of 
bandwagon effect, which is a kind of bandwagon effect that enterprises believe that it is worth imitating the best practices which are widely adopted by the market. The second way is the convergence pressure comes into being by imitating the competitors. If competitors can effectively adopt an innovative technology and benefit from it, rational enterprises will apply to this technology under the circumstance of competing. Therefore, imitativeness pressure is the important factor for enterprise to adopt XBRL technology.

2) Normalization pressure is one of the dominant factors for enterprise to adopt XBRL technology: Normalization pressure derives from the values and standards of conduct in the production sector, industry association and academic institutions, which can drive the organization to observe the professional regulations which have reached the pressure of legitimacy. When government adopts different diffusion polices, government will participate or guide the development of XBRL innovation technology in a direct or indirect way, which can provide adopters with a good external environment. Organizations or enterprises will certainly have some relevant understanding on this innovative technology, although this technology will not be complemented inside the company, enterprises will disclose and report some information to the outside world in accordance with the requirements and specifications. Moreover, the requirements of business partners and the attitudes of intermediaries such as accounting firms can also affect the adoption of new technology by enterprises. Similarly, the current mainstream values of the industry will also affect the technology implementation. Therefore, normative pressure is one of the dominant factors for enterprise to adopt XBRL technology.

\section{MOdEL TeSt OF STRUCTURAL EQUATION}

In order to test the influence of 7 factors to XBRL implementation, the writer adopts AMOS software's ongoing structural equation modeling to research the influence of 7 factors to implementation and diffusion of XBRL technology. The first model construction shall be conducted according to the theoretical construction. This research has 8 latent variables, of which the observational variable Q1 Q2 refers to the implementation and diffusion of XBRL technology, Q3 Q5 refers to technology complexity, Q6 Q8 refers to technology compatibility, Q9 Q11 technology refers to relative advantage of technology, Q12 Q14 refers to the cognition degree of technology, Q15 Q17 refers to learning publicity, Q18 Q20 refers to imitation pressure, and Q21 Q23 refers to normative pressure. The implementation and diffusion of XBRL technology are influenced directly by the technology complexity, technology compatibility, and relative advantage of technology, cognition degree of technology, learning publicity, imitation pressure and normative pressure. "Fig. 2"

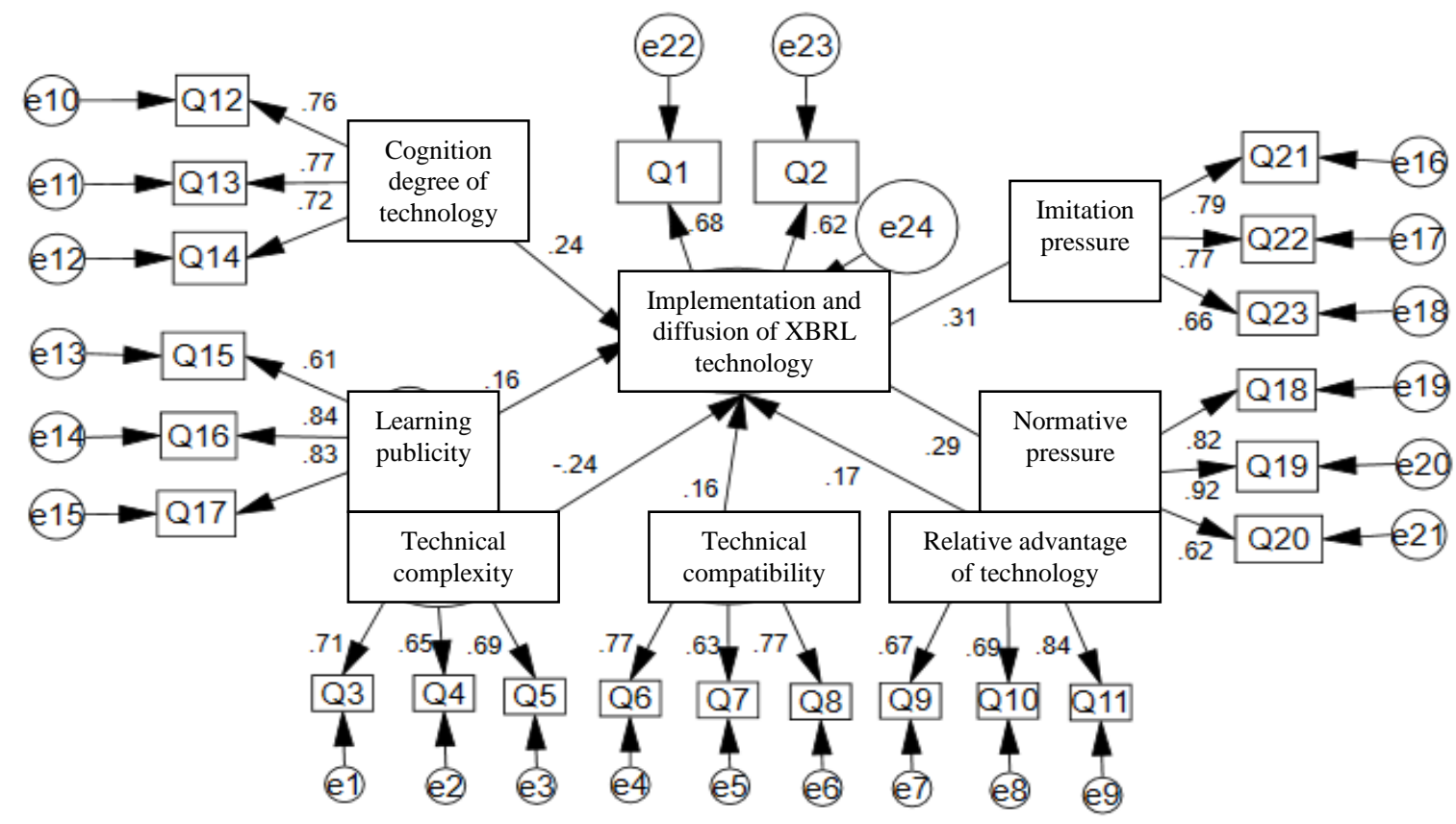

Fig. 2. Structural equation model adopted by XBRL and test results.

After model fitting, the inspection of violation estimation and model fitting shall be conducted. The model can be used to conduct model fitting test if it is found that no negative error variance in the model fitting, all the standardized coefficients of each method were not more than 0.95 and no violation estimation in the model.
The test of model fitting passed the valuation of absolute fitting index- RMSEA value and GFI value, the added-value fitting index-NFI and CFI, and the simple fitting index - ${ }^{2}$ /df. The results are in the following table "Table IV". The RMSEA value in absolute fitting index is 0.052 , which is below 0.08 and meets the standard. GFI is 0.902 , which is 
above 0.9 and meets the standard; NFI of added-value fitting index is 0.935 , CFI is 0.918 , all of which meets the standard; and the simple fitting index ${ }^{2} / \mathrm{df}$ is 1.796 , which is below 2 and meets the standard.

TABLE IV. INDEX RESULT OF MODEL'S FIRST FITTING

\begin{tabular}{llll}
\hline \multicolumn{1}{c}{ Value of statistical test } & Adaptive criteria or critical values & \multicolumn{1}{c}{ Value of inspection result } & Judgment of model fitting \\
\hline Absolute fitting index & & & \\
RMSEA value & $<0.08$ & 0.052 & yes \\
GFI value & $>0.9$ & & \\
Added-value fitting index & $>0.9$ & 0.935 & yes \\
NFI value & $>0.9$ & 0.918 & yes \\
CFI value & & & yes \\
Simple fitting index & $<2$ & 1.796 & yes \\
$\chi^{2 / d f}$ & & & \\
\hline
\end{tabular}

The results of each method are shown in the following table "Table V".

TABLE V. ANAlysis On Results of Method and Proof Situation OF ORIGinal Hypothesis

\begin{tabular}{|c|c|c|c|c|c|c|}
\hline $\begin{array}{l}\text { Hypothe } \\
\text { sis No. }\end{array}$ & Method analysis & $\begin{array}{l}\text { Standard } \\
\text { path coef }\end{array}$ & $\begin{array}{l}\text { Standard } \\
\text { Error }\end{array}$ & C.R. & $\mathbf{P}($ value $)$ & $\begin{array}{c}\text { Acceptance situation } \\
\text { of original } \\
\text { hypothesis }\end{array}$ \\
\hline $\mathrm{H} 1 \mathrm{a}$ & $\begin{array}{l}\text { Technical complexity } \rightarrow \text { implementation and } \\
\text { diffusion of XBRL technology }\end{array}$ & -0.243 & 0.09 & -2.918 & 0.004 & Accepted \\
\hline $\mathrm{H} 1 \mathrm{~b}$ & $\begin{array}{l}\text { Technical compatibility } \rightarrow \text { implementation and } \\
\text { diffusion of XBRL technology }\end{array}$ & 0.158 & 0.074 & 2.036 & 0.042 & Accepted \\
\hline $\mathrm{H} 1 \mathrm{c}$ & $\begin{array}{l}\text { Relative advantage of technology } \rightarrow \\
\text { implementation and diffusion of XBRL technology }\end{array}$ & 0.169 & 0.063 & 2.190 & 0.029 & Accepted \\
\hline $\mathrm{H} 2 \mathrm{a}$ & $\begin{array}{l}\text { Cognition degree of technology } \rightarrow \text { implementation } \\
\text { and diffusion of XBRL technology }\end{array}$ & 0.244 & 0.083 & 3.074 & 0.002 & Accepted \\
\hline $\mathrm{H} 2 \mathrm{~b}$ & $\begin{array}{l}\text { Learning publicity } \rightarrow \text { implementation and diffusion } \\
\text { of XBRL technology }\end{array}$ & 0.164 & 0.063 & 2.180 & 0.029 & Accepted \\
\hline $\mathrm{H} 3 \mathrm{a}$ & $\begin{array}{l}\text { Imitation pressure } \rightarrow \text { implementation and diffusion } \\
\text { of XBRL technology }\end{array}$ & 0.307 & 0.103 & 3.798 & $\mathrm{P}<0.001$ & Accepted \\
\hline $\mathrm{H} 3 \mathrm{~b}$ & $\begin{array}{l}\text { Normative pressure } \rightarrow \text { implementation and } \\
\text { diffusion of XBRL technology }\end{array}$ & 0.293 & 0.047 & 3.890 & $\mathrm{P}<0.001$ & Accepted \\
\hline
\end{tabular}

According to the method analysis, the most influential factor to implementation and diffusion of XBRL technology is the imitation pressure, the path coefficient is 0.307 $(\mathrm{t}=3.798, \mathrm{P}<0.001)$, Followed by the normative pressure, the path coefficient is $0.293(\mathrm{t}=3.890, \mathrm{P}<.0 .001)$, cognition degree of technology and its path coefficient is 0.244( $\mathrm{t}=3.074, \mathrm{P}=0.002)$, technical complexity, the path coefficient is $-0.243(\mathrm{t}=2.918, \mathrm{P}=0.004)$, the relative advantage of technology, the path coefficient is 0.169 $(\mathrm{t}=2.19, \quad \mathrm{P}=0.029)$, and learning publicity, the path coefficient is $(\mathrm{t}=2.18, \mathrm{P}=0.029)$; technical compatibility, the path coefficient is $0.158(\mathrm{t}=2.036, \mathrm{P}=0.042)$, which are positive effects and consistent with all assumptions.

\section{CONCLUSION}

It is found that the adoption and implementation of XBRL technology based on China's current context are mainly influenced by 7 factors including complexity, compatibility, comparative advantage, cognitive degree of organizational dimension, learning and propaganda, and the imitative stress factors and normative pressure factors in environmental dimensions. Therefore, in view of the above results, the following suggestions are put forward.

\section{A. In Order to Choose XBRL Software Reasonably, the} Enterprise's Current Situation Should Be Considered

XBRL technology matter is the key factor. The relevant professional and technical software and other tools' support are essential in the process of promotion and dissemination of XBRL technology. For the enterprise, besides strengthening the recognition of new technology, the choice of software is one of the factors to reduce costs. Combining with the particularity of enterprise, the enterprise shall choose the right software to better play the advantages of XBRL technology. At present, there are the professional modules supporting embedded XBRL financial reporting model at home and abroad. For example, foreign Oracle and SAP, as well as the domestic UF, Kingdee and wave products, these companies can choose XBRL products that matching their own financial products and database. In addition, companies should choose reliable software suppliers on the basis of cost. After all, the technical support and help are needed for the maintenance of late software upgrades, enterprise personnel training and other knowledge of pre-sale and after-sale service quality. So the reliable software would reduce the cost of maintenance and maintain the stability of software. 


\section{B. The Government Shall Enhance the Capital and Technology Inputs to Balance Market Demand}

The promotion and application of XBRL cannot be developed without the support of software system. First, the government shall not only increase the intensity of supervision, but also fund the expansion of XBRL in funding and technology. The U.S. Securities and Exchange Commission (SEC) invests billions of dollars in XBRL technology, which effectively promotes the research and development of technology. It also improve comparability, reliability and transparency of XBRL information a lot and keep the leading role in the world, which can be seen that there are great influence of government if it promotes the implementation of XBRL technology. Second, competition and incentive mechanism shall be introduced. The government can give the policy subsidies on the tax, which will provide people, financial and material support to the XBRL applications of software developers, consulting agencies and enterprises. Software developers shall be encouraged to conduct their own research, development and design of software considering technical compatibility, so as to introduce XBRL professional tools suitable for China's national conditions and industry market [7]-[9] as soon as possible. Meanwhile, the government shall fully develop the characteristic in combing XBRL and IT technology and improve its own technology advantages, which will lay the foundation for better technology diffusion.

\section{It Should Be Strengthened That the Popularization and Training of XBRL Professional Knowledge, So As to Train More Advanced and Comprehensive Talents Needed by the Society}

The difficulty of promotion of XBR technology application is lack of talent and technology, so it is imperative to cultivate comprehensive talents. Government, enterprises and colleges can cooperate with each other to integrate the resources, form the connection and jointly train a group of professional inter-disciplinary talents with financial, IT technology and XBRL international joint technology. The management shall be strengthened closely combined with the continuing education of the financial sector. It can be entrusted to universities or software companies to establish XBRL training base, and business accounting personnel shall be organized and taken turns regularly for learning. Their perception and understanding of XBRL shall be strengthened through a variety of new propaganda modes such as technology competitions, microblog and micro platform, etc, so as to improve the enthusiasm of small and medium sized enterprises to actively explore the best practice model of XBRL. Besides updating the professional financial knowledge, the financial staff shall also continue to learn and apply the new international technology, so as to close the high grade and comprehensive talents and actively participate in the promotion and popularization of XBRL technology.

\section{REFERENCES}

[1] Tomatzky L G,F leischer M. The Processes of Technological Innovation. Lexington, Massachusetts; Lexington Books, 1990 $117-148$.

[2] Gao Jinping, Audit Model and Realization Mechanism of XBRL Financial Report: A Framework Research [J]. Auditing Research, 2011,(3): 74-80.

[3] Kuan, K. Y. Chau, P. K.. A Perception - Based Model for EDI Adoption in Small Businesses Using a Technology - OrganizationEnvironment Framework [J]. Information \& Management, 2001, 38(8) : 507-521.

[4] Zhu, K., Kraemer, K. L., Xu, S. The Process of Innovation Assimilation by Firms in Different Countries: A Technology Diffusion Perspective on E-Business [J]. Management Science, 2006, 52(10) : 1557-1576.

[5] Peng Hongxia, Xu xianhao, Zhang Yuchuan. Research on the Determinants of RFID Adopted by Enterprises Based on TOE Framework [J]. Research on technology economy and management 2013,(11): 3-7.

[6] Zhang Tianxi. Network Finance Report: Research on the Theoretical Basis of XBRL Standards. [J] . Accounting Study, 2006 (9) : 5663

[7] Shi Yong, Zhang Longping. Research on the Effect of Financial Reporting - Based on the Perspective of Stock Price Synchronicity [J]. Accounting Study, 2014,03:3-10+95.

[8] Bonson, E., Cortijo, V. , Escobar, T. A Delphi Investigation to Explain the Voluntary Adoption of XBRL [J]. International Journal of Digital Accounting Review, 2009, 9( 2) : 193-205.

[9] Gunn, J. XBRL: Opportunities and Challenges in Enhancing Financial Reporting and Assurance Processes [J]. The Accounting Review Issues, 2007, 1(6) : 36-43.

[10] Shi Yong, Zhang Longping. Research on the Influence of Financial Reports to Analysts' Prediction.[J] Macroeconomic Research, 2014, 08:121 - 132 .

[11] Janvrin D J, Pinsker R E, Mascha M F. XBRL-Enabled, Spreadtable, or PDF? Factors Influencing Exclusive User Choice of Reporting Technology [J] . Journal of Information Systems, 2013, 27:35-49.

[12] Khadaroo I. Corporate Reporting on the Internet: Some Implications for the Auditing Profession [J]. Managerial Auditing Journal, 2005, volume 20(6):578-591.

[13] Kim J W, Lim J H, No W G The Erect of First Wave Mandatory XBRL Reporting across the Financial Information Environment [J]. Journal of Information Systems, 2012, 26(1):127-153. 